\title{
Vocabulary used by ethno-linguistically diverse South African toddlers: A parent report using the Language Development Survey
}

\author{
A Gonasillan, ${ }^{1} \mathrm{MA}(\mathrm{AAC})$; J Bornman, ${ }^{1} \mathrm{PhD} ;$ M Harty, ${ }^{1,2} \mathrm{PhD}$ \\ ${ }^{1}$ Centre for Augmentative and Alternative Communication, University of Pretoria, Pretoria, South Africa \\ ${ }^{2}$ Communication Sciences and Disorders, University of Cape Town, Cape Town, South Africa
}

Corresponding author: J Bornman (juan.bornman@up.ac.za)

\begin{abstract}
Objective. The primary aim of this study was to ascertain the relevance of the vocabulary of the Language Development Survey (LDS) for typically developing South African toddlers who attend ethno-linguistically diverse early childhood development centres.

Rationale. The need for exploration of the expressive vocabulary of this population stems from the diverse linguistic contexts to which toddlers are exposed on a day-to-day basis in South Africa. Many parents prefer English as the language of learning and teaching for their child. As a result, toddlers interact with ethno-linguistically diverse peers from a young age, usually within their early childhood development centres. Method. An adapted version of the LDS was presented to 40 middle-class parents in Mpumalanga. Vocabulary commonly used by toddlers was determined and a comparison of parent responses made between the present study and the original American-based survey.

Results. Results revealed that nouns were used most often by toddlers, in keeping with research on vocabulary acquisition. Significant correlations between the two groups were evident in 12 of the 14 categories. Parents reported that nouns, verbs, adjectives and words from other word classes were used similarly by toddlers, despite differences in their linguistic exposure.

Conclusions: These findings suggest that the LDS is a valuable clinical screening tool for speech-language therapists who deliver services to toddlers within the South African context.
\end{abstract}

Keywords: ethno-linguistically diverse, monolingual, parent report, toddlers' language development, vocabulary

S Afr J CD 2013;60:10-15. DOI:10.7196/SAJCD.124

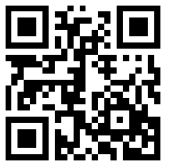

Irrespective of culture, the ability to use and understand language is essential to life, as language provides a mechanism for establishing interpersonal relationships, regulating the behaviour of others, satisfying needs and desires, exploring and organising the environment and exchanging information and additional messages with others (Cole, 1982). Toddlers must be taught the function of language and how to produce and use it in ways which are congruent with other members of their culture. Parents and other competent language users therefore prepare toddlers for learning language by first assisting them in experiencing and appreciating the pleasure, knowledge and security that emanate from social interaction. Research has indicated that the quality of the language input during these early years not only impacts significantly on the development of oral language skills, but also on later success in literacy (Bleses, Vach, Jørgensen \& Worm, 2010; Kelly, 2010; Rijlaarsdam et al., 2013).

Within the social constructivism approach to language development (Vygotsky, 1978) the role of more competent adult role models cannot be underestimated in the development of a child's language skills. Parents are the first communication partners a young child encounters and certainly remain the most influential during the early years (Schiff \& Lotem, 2013). Parents engage in the process of scaffolding, whereby they guide their child from simpler to more complex language forms. Scaffolding allows children to perform tasks that would normally be slightly beyond their ability without that assistance and guidance from the competent adult language user. As such, parents are experts in understanding and describing their child's language abilities. Research evidence shows that parents are good informants regarding their child's expressive language development and are able to provide accurate information pertaining to their child's language abilities (Feldman et al., 2005).

For this reason professionals often rely extensively on parent report as a supplementary assessment tool for understanding the language acquisition of young children (Dale, Bates, Reznick \& Morisset, 1989; Kelly, 2010). Parent diary studies have been used for over 50 years to explore the gradual development of child vocabulary (Berko, 1958; Bleses et al., 2010). However, because of the impracticality of these studies they were replaced with vocabulary checklists which are more structured, practical and easy to use (Rescorla, Alley \& Christine, 2001). Vocabulary checklists used in research with toddlers are the MacArthur Communicative Development Inventory (CDI) (Fenson et al., 2000) and the Language Development Survey (LDS) (Rescorla, 1989). The LDS, used in this study, was developed more than 20 years ago as a simple and inexpensive screening tool to identify expressive language delay in toddlers (Rescorla \& Achenbach, 2002). It can be completed in about 10 minutes, requires only primary school literacy skills, needs no professional staff for administration and is easy to score (Rescorla et al., 2001). Furthermore, it has good psychometric properties (Rijlaarsdam et al., 2013).

The LDS is a highly reliable instrument. Rescorla (1989) reported Cronbach alpha consistency of 0.99 for a 1-week test-retest in a sample of 81 toddlers, while Rescorla and Alley (2001) reported a test-retest reliability of $0.97(p<0.001)$ using the Pearson correlation in a sample of 66 toddlers whose mothers completed the LDS on two occasions, an average of 23 days apart.

The validity of the LDS has been demonstrated by numerous studies. In an epidemiological survey of 422 toddlers, Rescorla and Alley (2001) reported excellent concurrent validity, with high correlation between reported and tested vocabulary (0.69 and 0.74). Predictive validity measured by correlations between the LDS and the Reynell Expressive Language Scale were also very high $(0.78$ and 0.81$)$. Using language test performance as the 'gold standard' for 'true' delay, the LDS sensitivity has generally been $80 \%$ or better and the LDS specificity $85 \%$ or better (Rescorla, 1989; Rescorla \& Achenbach, 2002; Rescorla \& Alley, 2001). In summary, research shows that the LDS has good reliability, validity and clinical utility.

Since its inception, the LDS has undergone continuous revision with the goal of maximising coverage of important vocabulary items and minimising redundancy (Rescorla, 1989). The most recent revision contains 309 different words arranged in 14 semantic categories. 
This length seems sufficient to cover a large enough range of early vocabulary without being overwhelming (Rescorla, Mirak \& Singh, 2000).

The rationale for the development of vocabulary checklists is based on the assumption that language vocabularies of typically developing toddlers contain many of the same items. Chomsky (1965) first introduced this notion with his concept of a universal grammar. Subsequent researchers supported the idea that, irrespective of ethnic or linguistic background, children move through the same stages of early language development at a fairly predictable rate (Cole, 1982). Clark (1993) states that, globally, toddlers tend to talk about similar things such as people, food and body parts, while CunninghamAnderson and Anderson (1999) report that the rates and sequences of language development tend to be similar, regardless of how different the languages may be. Caselli, Casadio and Bates (1999) also found that the onset and subsequent growth of nouns, predicates, function words and social terms between English and Italian proved to be similar. This is evident as many of the same words appear in multiple checklists such as the CDI (Fenson et al., 1993) and the LDS (Rescorla et al., 2001). Hence the applicability of vocabulary checklists in monolingual contexts is well established (Dale et al., 1989).

A recent study by Barrat, Khoza-Shangase and Msimang (2012) emphasises the need for culturally and linguistically appropriate assessment tools in this country because of multilingualism and ethnic diversity. South Africa holds within its Constitution 11 official languages (South African Constitution, Act 108 of 1996) and approximately $36 \%$ of homes are bilingual and often use a combination of languages (Statistics South Africa, Census, 2011). In addition to these 'gold standard' formal assessment measures mentioned by Barrat et al. (2012), speech-language therapists should also gather information about the child's language functioning with parent-report measures such as the LDS (Rescorla, 1989; Rescorla \& Alley, 2001) or the CDI (Fenson et al. 2000), particularly for toddlers with varied cultural and linguistic systems (Kelly, 2010). The applicability of an easy-to-use screening checklist (such as the LDS) that compensates for parents who speak English as a second or third language (Rescorla, 1989) thus came under review. However, the data demonstrating that parents from bilingual homes are easily able to complete the checklist in English irrespective of whether or not English is their first language, all stem from the USA (Rescorla, 1989; Rescorla et al., 2000). Therefore, the applicability of the LDS in a multilingual context rich in ethnic diversity such as South Africa has yet to be established. This research aimed to ascertain the relevance of the vocabulary of the LDS for typically developing 2-year-old South African toddlers who attend ethno-linguistically diverse early childhood development centres.

\section{Method \\ Objective}

The primary aim of the study was to ascertain the relevance of the vocabulary of the LDS for typically developing 2-year-old South African toddlers who attend early childhood development centres that use English as the medium of instruction, through parent report. Two subaims informed the primary aim of the study: (i) to describe what South African parents report as commonly used vocabulary items by toddlers; and (ii) to compare parents' responses using the LDS-SA (present study) and the LDS (original survey conducted in Pennsylvania, USA).

\section{Design}

A comparative cross-sectional survey design using an existing checklist was employed. Comparisons were made using the Spearman rank order correlation coefficient $(r)$. Based on these results the LDS checklist was verified for toddlers developing within an ethno-linguistically diverse context in South Africa.

\section{Participants}

Parents were recruited from eight similar privately owned early childhood development centres within the Emalahleni area, using a purposive sampling approach. Emalahleni, also known as Witbank, is a growing metropolis within the Mpumalanga province. It is a mining community and home to diverse ethnic and linguistic groups. Early childhood development centres were contacted and asked to participate if they had 2-year-old toddlers, were within the specified demographic area and were willing to assist the researchers in recruiting parents from their school.

Eighty per cent of parents who completed the survey instrument were mothers of the toddlers and their ages ranged from 22 to 42 years old. Fifty per cent of participants had obtained a college or university degree, $25 \%$ a partial college qualification, $20 \%$ had completed grade 12 and $5 \%$ grade 10 or 11 . The majority of parents $(80 \%)$ were married, while $13 \%$ were single. The remaining $7 \%$ either did not disclose their marital status or were divorced. Less than half $(45 \%)$ did not have any additional children, implying that they were first-time parents. Of those who had more than one child, $40 \%$ had only one other child while $13 \%$ indicated they had two or more other children. Only $3 \%$ had more than two other children. All parents were employed and could afford to send their child to an early childhood development centre. Ninety-five per cent of parents earned a household income of more than R4 500 per month. The remaining 5\% who earned an income less than this amount were primarily from single-parent households. A monthly income of less than R4 500 is not taxable according to the South African Revenue Service (SARS).

An equal percentage of parents spoke isiZulu or English at home (33\%), with 25\% speaking Afrikaans, 5\% Sepedi and 3\% speaking either SiSwati or Setswana. Thus, a total of 6 of the 11 official South African languages were spoken at home. Additionally, $74 \%$ of parents also spoke English to their child at home. All early childhood development centres used English as the medium of instruction, although toddlers were from varying ethno-linguistic backgrounds.

\section{Materials}

A demographic questionnaire was developed to obtain biographical data from parents. It was designed according to the Hollingshead (1975) four-factor index of social status and included gender, marital status, education level and occupation of parents. Parents were also requested to disclose their monthly income, report on the general development and language development of the child and describe what their home language was, whether multiple languages were used in the household and whether English was spoken to the toddler at home.

Together with the demographic questionnaire, the LDS formed the main instrument used during data collection. The 309 different words included in the LDS are arranged in 14 semantic categories (191 nominals and 118 non-nominals) (Rescorla et al., 2000). The categories are: Food, Toys, Vehicles, Places, Actions, Outdoors, Animals, Body parts, Household, People, Personal, Clothes, Modifiers and Other. All words within these categories can be classified as nouns except for those in the categories Action, Modifiers and Other (Rescorla et al., 2000).

Before distribution of the checklist to participants in the pilot study, a subject matter expert panel was used to determine the suitability of vocabulary for the South African context (Gonasillan, 2011). The panel consisted of 2 teachers, 1 occupational therapist, 4 speech-language therapists, 2 augmentative and alternative communication (AAC) specialists and the mother of a child with language impairment. The duration of their experience of working with children ranged from 6 to 24 years. It was agreed that 22 vocabulary items on the original checklist be replaced by their South African equivalents in order to ensure cultural, metric and linguistic equivalence (Bornman, Sevcik, Romski \& Pae, 2010). These items are shown in Table 1.

The suitability of the suggested vocabulary adaptations was then tested with five typically developing preschool children. Their ages ranged from 3:0 years to 6:11 years. The results confirmed the adapted vocabulary items for use in the pilot study.

\section{Pilot study}

A pilot study was conducted to ensure accuracy of materials and procedures before commencing the main research project. The researcher selected 1 of the 8 early childhood development centres as a pilot site in a geographical area similar to the main study. Ten parents were invited to participate, 5 of whom agreed. The pilot study confirmed the clarity of written instructions for parents and the 
appropriateness of the visual layout for the demographic questionnaire and checklist (LDS-SA). It also determined the suitability of the data collection method. No modifications were necessary to either the data collection procedures or the written instructions and visual layout of the forms.

\section{Procedures}

The forms were sent home in a sealed envelope in the toddlers' school bags. Parents were requested to return the completed form to the principal within the week of receiving it. Eighty forms were distributed by principals, and of 60 returned forms, 40 indicated that the parents agreed to participate in the study, 15 did not wish to participate and 4 parents committed to the study but did not return their forms before the specified cut-off date. Only one set of data was excluded as the specific toddler did not meet the required 2-yearold age specification. Therefore a response rate of $50 \%$ was obtained.

\section{Data analysis}

Descriptive statistics formed the basis of the data analysis procedure. Information from the biographic questionnaire and LDS-

\begin{tabular}{|c|c|}
\hline \multicolumn{2}{|c|}{ Cultural equivalence } \\
\hline $\begin{array}{l}\text { Language } \\
\text { Development } \\
\text { Survey }\end{array}$ & $\begin{array}{l}\text { South African } \\
\text { equivalent }\end{array}$ \\
\hline soda & coke \\
\hline pretzel & chips \\
\hline candy & sweets \\
\hline sweater & jersey \\
\hline sneakers & takkies \\
\hline diaper & nappy \\
\hline bottom & bum \\
\hline peepee & weewee \\
\hline nap & sleep \\
\hline belly & tummy \\
\hline cracker & salty biscuit \\
\hline gum & bubblegum \\
\hline cookie & biscuit \\
\hline mittens & gloves \\
\hline trash & rubbish \\
\hline stroller & pram \\
\hline sidewalk & pavement \\
\hline crib & $\cot$ \\
\hline store & shop \\
\hline bathtub & bath \\
\hline turtle & tortoise \\
\hline \multicolumn{2}{|c|}{ Metric equivalence } \\
\hline penny & money \\
\hline
\end{tabular}

SA were coded in an Excel spreadsheet. Inferential statistics were applied to the data and comparisons were drawn between the South African study (LDS-SA) and the Pennsylvanian sample described by Rescorla et al. (2001). In Rescorla et al's survey mothers within the Pennsylvania community completed the checklist $(n=422)$ as part of a larger epidemiological survey of language abilities of toddlers. Rescorla et al. (2001) provide the frequencies for each of the items on the checklist in an appendix which was included in the published manuscript. These data were used in the comparative analyses. The Spearman rank order correlation coefficient $(r)$ was computed for each semantic category and the strength of the correlation between categories for the LDS-SA and LDS samples was assessed.

\section{Results \\ Commonly used vocabulary items in the South African context}

Parents were asked to complete the checklist by marking one of two columns to indicate the presence or absence of the item in the child's current lexicon. For this sample $(n=40)$ a percentage value for every word was computed, based on the number of toddlers reported to produce that word relative to the total sample. Using these data, 24 items were reported in the lexicons of $90-100 \%$ of the sample of 40 typically developing toddlers. These high-frequency words can be regarded as 'commonly used' items within the vocabulary of toddlers from this context (Table 2). Thirteen of these items were nouns and 8 were verbs. The remaining 3 items fell into the Other category and included the

Table 2. Vocabulary items most commonly used by South African toddlers

\begin{tabular}{|c|c|c|c|}
\hline Semantic categories & $\begin{array}{l}\text { Vocabulary } \\
\text { items }\end{array}$ & $\begin{array}{l}\text { Number of } \\
\text { participants } \\
\text { reporting use }(n=40)\end{array}$ & $\begin{array}{l}\text { Percentage of } \\
\text { sample reporting } \\
\text { use }\end{array}$ \\
\hline \multicolumn{4}{|l|}{ Nouns (182 items) } \\
\hline Places: & - & & - \\
\hline Vehicles: & car & 36 & $90 \%$ \\
\hline \multirow[t]{2}{*}{ Toys: } & ball & 36 & $90 \%$ \\
\hline & book & 36 & $90 \%$ \\
\hline Outdoor: & - & & - \\
\hline Personal: & - & & - \\
\hline \multirow[t]{2}{*}{ People: } & daddy & 37 & $93 \%$ \\
\hline & mommy & 36 & $90 \%$ \\
\hline Clothes: & shoes & 36 & $90 \%$ \\
\hline Animals: & fish & 36 & $90 \%$ \\
\hline Body parts: & eye & 36 & $90 \%$ \\
\hline \multirow[t]{4}{*}{ Food: } & juice & 38 & $95 \%$ \\
\hline & chips & 37 & $93 \%$ \\
\hline & tea & 37 & $93 \%$ \\
\hline & sweets & 36 & $90 \%$ \\
\hline Household: & bed & 38 & $95 \%$ \\
\hline \multicolumn{4}{|l|}{ Verbs (54 items) } \\
\hline \multirow[t]{8}{*}{ Actions: } & sit & 38 & $95 \%$ \\
\hline & come & 37 & $93 \%$ \\
\hline & eat & 37 & $93 \%$ \\
\hline & bath & 36 & $90 \%$ \\
\hline & go & 36 & $90 \%$ \\
\hline & kiss & 36 & $90 \%$ \\
\hline & open & 36 & $90 \%$ \\
\hline & see & 36 & $90 \%$ \\
\hline \multicolumn{4}{|l|}{ Adjectives (31 items) } \\
\hline Modifiers: & - & & \\
\hline \multicolumn{4}{|l|}{ Other (31 items) } \\
\hline Prepositions: & - & & \\
\hline \multicolumn{4}{|l|}{ Onomatopoeia: } \\
\hline Social phrases: & no & 37 & $93 \%$ \\
\hline Numbers: & $\begin{array}{l}\text { one, two, } \\
\text { three }\end{array}$ & 37 & $93 \%$ \\
\hline Greetings: & hi/hello & 36 & $93 \%$ \\
\hline Letters: & - & & \\
\hline Interrogatives: & - & & \\
\hline
\end{tabular}


social phrase hi/hello; the negative no and numbers one, two, three, etc. No items from the Modifiers category could be classified as high-frequency vocabulary items within this sample.

\section{Comparisons between the frequency of vocabulary item use for the two samples}

The use of items across the 14 semantic categories was initially investigated by determining a percentage of word use within each semantic category for each of the two samples and then comparing the data. Generally, parent responses from the South African study appear similar to the responses reported from the American-based study (Rescorla et al., 2001). The bar graph in Figure 1 shows small differences between word usage from the two samples with one category indicating no difference at all (Toys). Besides the categories of Actions and Modifiers (which obtained response differences between the two participant groups of $20 \%$ and $11 \%$ respectively) the remaining 11 categories showed differences of $10 \%$ or less. The category Places was the only category in which parents from the current study reported lower use of vocabulary items than those parents who formed part of the American study (Rescorla et al., 2001). In all of the remaining categories the parents of the current study reported higher usage of the vocabulary items on the checklist. This highlights the similarity of parent responses on the checklist.

Word frequencies (word usage) from the two samples were compared using the Spearman rank order correlation coefficient $(r)$ across the 14 semantic categories. A high correlation statistic indicates that highfrequency words used within one sample were also very common in the lexicon of the other sample. The results of these analyses can be viewed in Table 3. The correlation between 10 of the 14 categories was significant at the 5\% level. This further indicates that the parent- reported usage of lexical items from the two studies was similar. The highest correlations $(r \geq 0.60)$ were found for the Places, Body parts, Personal, Toys, People and Other categories. Clothes, Vehicles, Outdoors and Animals were not statistically significant $(p \geq 0.05)$.

Assessment of the individual percentages for items in these categories showed that jersey, boots, gloves, slippers, coat and belt within the Clothes category, bus, motor bike, trolley and plane within the Vehicles category, snow in the Outdoors category and chicken and snake within the Animals category appeared to be items which displayed the greatest discrepancy between the two samples.

Overall, parents from both the South African and American samples showed that their 2-year-old toddlers used similar vocabulary, regardless of their linguistic background. The LDS-SA therefore presents as one possible method for capturing the vocabulary used by South African toddlers in the context in which the data were collected.

\section{Discussion}

The 24 vocabulary items found to be commonly used by South African toddlers correlate with research results on early acquisition of vocabulary. Nelson (1973) found that the majority of early words of 18 toddlers consisted of nouns and included family members, toys, food items, parts of the body, and items of clothing. Similarly, commonly used vocabulary items by the South African toddlers fell within the categories Vehicles, Toys, People, Clothes, Animals, Body parts, Food and Household. These data suggest that commonly used words within the South African context are also embedded within routine activities in the toddlers' lives, in keeping with experiences from other Western societies where parents assist the language learning process by using familiar phrases for regular routines (Trivette, Dunst \& Hamby, 2004).

The literature states that as expressive vocabulary grows, the majority of words

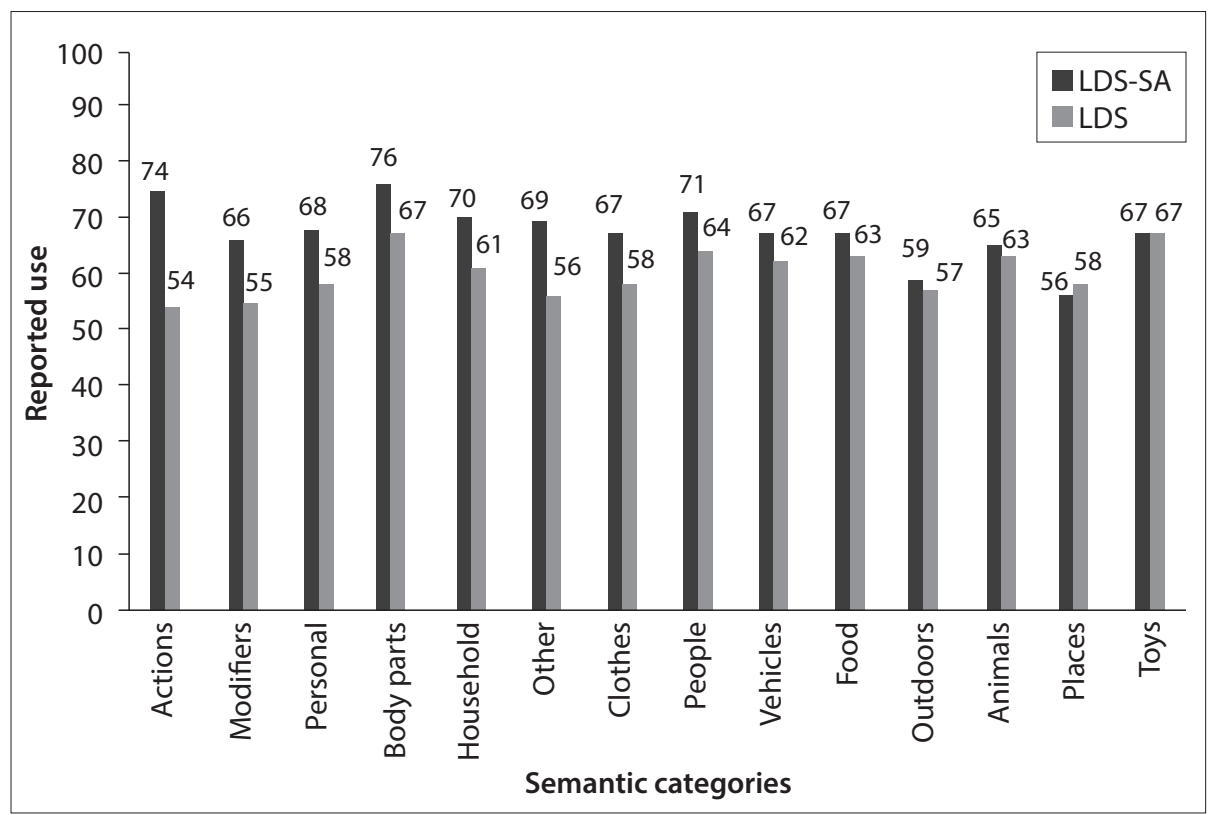

developed are nouns, although differences along the developmental journey are acknowledged (Caselli et al., 1999). Gentner (1982) argued that nouns must precede verbs in early language development because the concept of an object (noun) is easier to grasp than an action (verb). This idea, however, has been challenged recently in cross-linguistic studies. For instance, it seems that for Korean and Chinese children knowledge of nouns does not develop in the same manner as in children learning English (Choi \& Gopnik, 1995; Tardiff, 1996). Tardiff (1996) claims that verbs may actually predominate over nouns in early language acquisition for many Chinese children. Makin, Campbell and Diaz (1995) suggested that while nouns are developing, there is a simultaneous large increase in words related to actions.

Results from this study suggest that there is a $20 \%$ difference in the usage of items in the Action category between the two groups of toddlers. This would seem to imply that the ethno-linguistically diverse toddlers in this study were using more verbs than the monolingual participants in the original study. One explanation may be that they are all in an early childhood development centre which provides them with many opportunities for interaction and engagement. The likelihood of activity settings which are structured to enhance communicative development and to create learning opportunities would be evident within the centre's environment. Research is needed in order to probe this issue further. While building their vocabulary in their second year of life, toddlers are becoming more physically active (Anisfeld, 1984). Their words therefore reflect all the

Table 3. Spearman rank-order correlation coefficient values for the fourteen semantic categories between the LDS-SA and the LDS

\begin{tabular}{lll}
\hline Variable & $\begin{array}{l}\text { Spearman } \\
\text { rank-order } \\
\text { coefficient }(r)\end{array}$ & $p$ value \\
\hline Actions & 0.43 & $0.0011^{*}$ \\
Modifiers & 0.42 & $0.0185^{*}$ \\
Personal & 0.74 & $0.0056^{*}$ \\
Body parts & 0.82 & $<0.0001^{*}$ \\
Household & 0.45 & $0.0119^{*}$ \\
Other & 0.69 & $<0.0001^{*}$ \\
Clothes & 0.037 & 0.1688 \\
People & 0.61 & $0.0209^{*}$ \\
Vehicles & 0.49 & 0.1541 \\
Food & 0.45 & $0.0123^{*}$ \\
Outdoors & 0.52 & 0.0997 \\
Animals & 0.44 & 0.0517 \\
Places & 0.72 & $0.0446^{*}$ \\
Toys & 0.67 & $0.0220^{*}$ \\
*Significant at the $5 \%$ level $(p<0.05)$ & \\
& &
\end{tabular}

Fig. 1. Differences between categories for the LDS-SA and LDS. 
important aspects of daily life, including those for touching, tasting, climbing, falling, exploring, getting hurt, seeking comfort, turning away, rejecting food or attention, as well as getting and giving kisses and cuddles (Makin et al., 1995).

Traditionally there has been concern about the overall impact of exposure to ethno-linguistically diverse contexts (McLaughlin, 2006). Interventionists have feared that conflict between different languages may delay the acquisition of one or all of the languages being acquired. However, Caselli et al. (1999) discovered that the onset and development of nouns, predicates, function words and social terms were quite similar for both English-speaking and Italian-speaking children. As was evident in this exploratory South African study, many toddlers were exposed to languages other than English, either within their home or early childhood development centre; however, the comparison with the original survey revealed similar trends in the acquisition of vocabulary. The close agreement of parent responses from both the South African-based study and the original American one is supported by the $p$ values shown in Table 3. In many categories the South African toddlers appear to use more vocabulary items than their monolingual peers (see Figure 1).

The categories Clothes, Vehicles, Animals and Outdoors were the only four categories in which the positive correlations were not statistically significant ( $p=0.1688 ; p=0.1541 ; p=0.0517$ and $p=0.0997$ respectively). In addition, Places is the only category where the original participants showed greater usage of vocabulary items. This is not surprising given the fact that clothes, vehicles and places are more heavily linked to geographic and cultural or community factors (such as weather and the availability of amenities such as hospitals and zoos). Once again this highlights the importance of ensuring that items on a modified assessment measure are sensitive to such differences.

Overall, although only a small sample of the larger South African community was drawn, results from the South African study confirmed the vocabulary on the LDS-SA as useful for toddlers developing within the South African context. Additionally, despite ethno-linguistic differences between parents, South African toddlers used similar vocabulary to communicate about their everyday life activities.

\section{Study limitations}

An obvious methodological limitation of the study was the small number of participants $(n=40)$ compared with that of the original survey $(n=758)$. This may have impacted on the comparisons drawn between the two studies. South African participants, according to their disclosed biographical information, were from the middle-class socioeconomic group only and were literate. This was influenced by the recruiting procedures used. Data from parents who did not send their toddlers to early childhood development centres or who were illiterate were not included in the study. The group of participants was therefore not a true reflection of the South African population. Results cannot be generalised beyond the context in which the data were collected.

\section{Conclusions and recommendations}

The most important clinical implication of this study is that it confirmed that the LDS-SA may be one language screening tool that could be used with 2-year-old toddlers from ethno-linguistically diverse South African backgrounds. It meets the general benchmark of a screening tool, i.e. being brief, simple to administer, having objective scoring procedures, good psychometric properties, clear instructions and scientific and financial acceptability (Bleses et al., 2010). This study also provided evidence suggesting that, although the South African toddlers were from ethno-linguistically diverse contexts, the acquisition of vocabulary followed the same trend as reflected in their monolingual peers from the original study, as reflected by the close similarity of parent responses. It also provides insight into understanding which vocabulary items are commonly used by typically developing South African toddlers who are acquiring English in conjunction with another language.

Many South African toddlers from low socio-economic backgrounds do not have access to early childhood development centres. In future, inclusion of parents with 2-year-old toddlers from different settings (e.g. community clinics) is recommended. Using the same checklist with non-literate South African parents would be useful in determining the impact that parental literacy levels may have on the language development of their toddlers. Translation of the checklist into South Africa's eleven official languages would enable inclusion of ethnolinguistically diverse participants who do not speak English in research concerning language development in South African toddlers.

Many South-African-based speech-language therapists are faced with the challenge of assessing/treating multilingual children with language impairments on a daily basis (Pascoe et al., 2010). The data from this study suggest that the LDS-SA is an appropriate screening tool to document the vocabulary of South African toddlers developing language within an ethno-linguistically diverse context. The vocabulary on the LDS-SA therefore serves as a resource in guiding intervention efforts of South African speech-language therapists.

Acknowledgements. The authors wish to thank all the principals and parents who participated in this study. This study was completed in partial fulfilment of the requirements for the first author's master's degree in the Centre for Augmentative and Alternative Communication at the University of Pretoria. We also acknowledge the financial assistance of the National Research Foundation (NRF) towards this research project. Opinions expressed in this paper, as well as the conclusions drawn, are those of the authors and not necessarily attributable to the NRF.

\section{References}

Anisfeld, M. (1984). Language development from birth to three. Hillsdale, NJ: Lawrence Erlbaum Associates Inc.

Barrat, J., Khoza-Shangase, K. \& Msimang, K. (2012). Speech-language assessment in a linguistically diverse setting: Preliminary exploration of the possible impact of informal 'solutions' within the South African context. South African Journal of Communication Disorders, 59, 34-44. doi:10.7196/SAJCD.5

Berko, J. (1958). The child's learning of English morphology. In O. L. Taylor (Ed.), Nature of communication disorders in culturally and linguistically diverse populations (pp. 150177). San Diego: College-Hill Press.

Bleses, D., Vach, W., Jørgensen, R.N. \& Worm, T. (2010). The internal validity and acceptability of the Danish SI-3: A language-screening instrument for 3-year-olds. J Speech Lang Hear Res, 53, 490-507. doi:10.1044/1092-4388(2009/08-0132).

Bornman, J., Sevcik, R., Romski, M. A. \& Pae, H. K. (2010). Successfully translating language and culture when adapting assessment measures. Journal of Policy and Practice in Intellectual Disabilities, 7, 111-118. doi:10.1111/j.1741-1130.2010.00254.x

Caselli, C., Casadio, P. \& Bates, E. (1999). A comparison of the transition from first words to grammar in English and Italian. J Child Lang, 26, 69-111.

Choi, S. \& Gopnik, A. (1995). Early acquisition of verbs in Korean: A cross-linguistic study. J Child Lang, 22, 497-529.

Chomsky, N. A. (1965). Aspects of the theory of syntax. Cambridge, MA: MIT Press.

Clark, E. V. (1993). The lexicon in acquisition. Cambridge: Cambridge University Press.

Cole, P.R. (1982). Language disorders in preschool children. Englewood Cliffs, NJ: PrenticeHall Inc.

Cunningham-Anderson, U. \& Anderson, S. (1999). Growing up with two languages: A practical guide. New York, NY: Routledge.

Dale, P. S., Bates, E., Reznick, J. S. \& Morisset, C. (1989). The validity of a parent report instrument of child language at twenty months. J Child Lang, 16, 239-249

Feldman, H.M., Campbell, T.F., Kurs-Lasky, M., Rockette, H.E., Dale, P.S., Colborn, K. \& Paradise, J.L. (2005). Concurrent and predictive validity of parent reports of child language at ages 2 and 3 years. Child Dev, 76 (4), 1-20. doi:10.1111/j.14678624.2005.00882.x

Fenson, L., Dale, P. S., Reznick, J. S., Thal, D., Bates, E., Hartung, J. P., Pethick, S. \& Reilly, J. (1993). The MacArthur Communicative Development Inventories: User's guide and technical manual. San Diego: Singular Publishing Company

Fenson, L., Pethick, S., Renda, C., Cox, J.L., Dale, P.S. \& Reznick, J.S. (2000). Shortform versions of the MacArthur Communicative Development Inventories. Applied Psycholinguistics, 21, 95-116.

Gentner, D. (1982). Why are nouns learned before verbs: Linguistic relativity versus natural partitioning. In S. Kuczaj II (Ed.), Language Development Culture. Hillsdale, NJ Erlbaum.

Gonasillan, A. (2011). Vocabulary used by toddlers who attend ethno-linguistically diverse early childhood development centres: A parent report. University of Pretoria: Electronic Theses and Dissertations. Retrieved from: http://upetd.up.ac.za/thesis/available/etd10182011-124346

Hollingshead, A. B. (1975). The four-factor index of social status. Unpublished manuscript, Yale University

Kelly, D.J. (2010). Language acquisition challenges for preschoolers residing in low SES-households: Implications for speech-language pathologists and developmental researchers. Perspectives on Language Learning and Education. 17, 41-48. doi:10.1044/ lle17.2.41

Makin, L., Campbell, J. \& Diaz, C. J. (1995). One childhood many languages: Guidelines for early childhood education in Australia. Perth: Harper Educational. 
McLaughlin, S. (2006). Introduction to language development ( $2^{\text {nd }}$ ed.). New York: Thomson. Nelson, K. (1973). Structure and strategy in learning to talk. Monographs of the Society for Research in Child Development, 38 (1-2, Serial No. 149). New York, NY: Russell Sage Foundation.

Pascoe, M., Maphalala, Z., Ebrahim, A., Hime, D., Mdladla, N., Mohamed, M. \& Skinner, M. (2010). Children with speech difficulties: An exploratory survey of clinical practice in the Western Cape. South African Journal of Communication Disorders, 57, 66-75.

Rescorla, L. (1989). The Language Development Survey: A screening tool for delayed language in toddlers. Journal of Speech and Hearing Disorders, 54, 587-599.

Rescorla, L. \& Achenbach, T.M. (2002). Use of the Language Development Survey (LDS) in a national probability sample of children 18 - 35 months old. J Speech Lang Hear Res, 44, 733-743.

Rescorla, L. \& Alley, A. (2001). Validation of the Language Development Survey (LDS): a parent report tool for identifying language delay in toddlers. J Speech Lang Hear Res, 44, 434-445. doi:10.1044/1092-4388(2001/035)

Rescorla, L., Alley, A. \& Christine, J. B. (2001). Word frequencies in toddlers' lexicons. J Speech Lang Hear Res, 44, 598-609.

Rescorla, L., Mirak, J. \& Singh, L. (2000). Vocabulary growth in late talkers: lexical development from 2:0 to 3:0. J Child Lang, 27, 293-311.
Rijlaarsdam, J., Tiemeier, H., Hofman, A., Jaddoe, V.W.V., Mackenbach, J.P., Verhulst, F.C. \& Stevens, G.W.J.M. (2013). Home environments of infants: relations with child development through age 3. J EpidemiolCommunity Health, 67, 14-20. doi:10.1136/ jech-2012-200987

Schiff, R. \& Lotem, E. (2013). Effects of morphological awareness on children's word reading development from two socioeconomic backgrounds. First Language, 31(2), 139-16. doi:10.1177/0142723710393098

South African Constitution. (1996). South African Bill of Rights. Retrieved 19 February 2013 from http://www.rebirth.cp.za/billofrights.SA1.htm

Statistics South Africa - Census. (2011). Retrieved from http://www.mobi.statssa.gov.za/ census/first\%20Language.html.

Tardiff, T. (1996). Nouns are not always learned before verbs: Evidence from Mandarin speakers' early vocabularies, Dev Psychol, 32, 492-504.

Trivette, C., Dunst, C. \& Hamby, D. (2004). Sources of variation in consequences of everyday activity setting on child and parent functioning. Perspectives in Education, 22, 17-33.

Vygotsky, L. S. (1978). Mind in society: The development of higher psychological processes. Cambridge, MA: Harvard University Press. 